\title{
Invitation to Engage: Innovative and Collaborative Approaches to Diversifying the STEM Professoriate
}

\author{
Autumn M. Reed, Ph.D., and Renetta G. Tull, Ph.D. \\ University of Maryland, Baltimore County,USA, autumn2@umbc.edu, rtull@umbc.edu
}

\begin{abstract}
In order to address the challenges of the XXI century, especially those related to global sustainability, it is critical that institutions of higher education recruit, retain, and advance a diverse and excellent STEM professoriate. Notwithstanding awareness and programmatic interventions such as the National Science Foundation's Alliances for Graduate Education and the Professoriate (AGEP) program and $A D V A N C E$ program, in the United States, African Americans, Hispanic/Latinos, and women remain underrepresented at all points along the pathway to the STEM professoriate. This paper highlights the University of Maryland, Baltimore County's (UMBC) efforts to acknowledge and directly confront its own challenges with faculty diversity in STEM through innovative approaches and partnerships under the rubric of "Invitation to Engage." We hope that our conversations about this pressing issue, along with a review of our expanded approaches, will encourage other institutions to examine their current practices, and serve as an adaptable model to enact change. Through this paper we issue an open invitation for others to critically engage in these dialogues and to develop and take impactful and novel actions to repair the pathway to the STEM professoriate.
\end{abstract}

Keywords-Faculty Diversity, Engagement, Recruitment, Retention

Digital Object Identifier (DOI):

http://dx.doi.org/10.18687/LACCEI2016.1.1.092

ISBN: 978-0-9822896-9-3

ISSN: $2414-6390$

$14^{\text {th }}$ LACCEI International Multi-Conference for Engineering, Education, and Technology: "Engineering Innovations for Global Sustainability", 20-22 July 2016, San José, Costa Rica. 


\title{
Invitation to Engage: Innovative and Collaborative Approaches to Diversifying the STEM Professoriate
}

\author{
Autumn M. Reed, Ph.D., and Renetta G. Tull, Ph.D. \\ University of Maryland, Baltimore County, USA, autumn2@umbc.edu, rtull@umbc.edu
}

\begin{abstract}
Resumén-Con el fin de abordar los retos del siglo XXI, especialmente aquellos relacionados a la sostenibilidad global, es de suma importancia que las instituciones de educación superior incorporen, retengan y promuevan una facultad diversa y de alto grado en el área de STEM. A pesar de los esfuerzos de concientización e intervención de programas como el Alliances for Graduate Education and the Professoriate (AGEP) y ADVANCE de la Fundación Nacional de Ciencia (NSF), existe en los Estados Unidos una baja representación de africano americanos, hispanos/latinos, y mujeres en la vía a formar parte de la facultad en el área de STEM. Este trabajo subraya los esfuerzos realizados en la Universidad de Maryland, Baltimore County (UMBC) para sacar a relucir y confrontar directamente dichos retos en su propia facultad de STEM utilizando innovadores enlaces y enfoques bajo la rúbrica "Invitación a Participar". Esperamos que nuestro dialogo sobre esta cuestión apremiante y el resumen de nuestro amplio enfoque aliente a otras instituciones a examinar sus prácticas internas y sirvan como modelo para promover el cambio. A través de este trabajo ofrecemos una invitación abierta para que otros también aborden críticamente estos diálogos y desarrollen acciones innovadoras para reparar la trayectoria para formar parte de la facultad en STEM.
\end{abstract}

Abstract- In order to address the challenges of the XXI century, especially those related to global sustainability, it is critical that institutions of higher education recruit, retain, and advance a diverse and excellent STEM professoriate. Notwithstanding awareness and programmatic interventions such as the National Science Foundation's Alliances for Graduate Education and the Professoriate (AGEP) program and $A D V A N C E$ program, in the United States, African Americans, Hispanic/Latinos, and women remain underrepresented at all points along the pathway to the STEM professoriate. This paper highlights the University of Maryland, Baltimore County's (UMBC) efforts to acknowledge and directly confront its own challenges with faculty diversity in STEM through innovative approaches and partnerships under the rubric of "Invitation to Engage." We hope that our conversations about this pressing issue, along with a review of our expanded approaches, will encourage other institutions to examine their current practices, and serve as an adaptable model to enact change. Through this paper we issue an open invitation for others to critically engage in these dialogues and to develop and take impactful and novel actions to repair the pathway to the STEM professoriate.

Keywords - Faculty Diversity, Engagement, Recruitment, Retention

Digital Object Identifier (DOI): http://dx.doi.org/10.18687/LACCEI2016.1.1.092 ISBN: 978-0-9822896-9-3

ISSN: $2414-6390$

\section{INTRODUCTION}

Institutions of higher education in the United States are at a critical crossroads to recruit, retain, and advance an increasingly ethno-racially and gendered diverse professoriate. While significant gains have been made in the number of women engineering tenure and tenure-track (T/TT) faculty, which have increased to $15.2 \%$ in fall 2013 from $8.9 \%$ in 2001 [1], the number of faculty from underrepresented minority groups (URM) remains disproportionately low. As of 2014, African Americans represented 2.5\% of T/TT engineering faculty, Hispanics 3.9\%, and collectively, the numbers of American Indian, Native Hawaiian and Pacific Islanders are too small for comparison [2]. The causes for the disproportionate underrepresentation of the two largest ethnoracial groups, African Americans and Hispanics, who comprise $13.2 \%$ and $17.4 \%$ percent of the U.S. population respectively, are deep-rooted, complex, and often selfreinforcing ranging from climate issues to lack of critical mass [3]. Programs such as the National Science Foundation's (NSF) Alliances for Graduate Education and the Professoriate (AGEP) program and the NSF's ADVANCE program have raised awareness about gender and ethno-racial inequality in engineering and other sciences, but as the numbers demonstrate, these programmatic interventions have primarily benefited women from majority groups (read: white). The persistent disparity of engineering faculty from URM groups is indicative of a pervasively broken pathway to the professoriate. In order to address the pressing issues of the $21^{\text {st }}$ century, including finding solutions related to global sustainability, it is critical that we have a diverse and excellent professoriate. Indeed, the glaring ethno-racial disparities in the STEM professoriate are a direct impediment to discovering and creating solutions related to global sustainability and the sustainability of institutions of higher education. In light of the failure to meaningfully broaden participation, universities must radically rethink and retool their approaches to remedying these systematic inequalities - their sustainability depends on it.

The University of Maryland, Baltimore County (UMBC), known nationally in the United States as a model for inclusive excellence in STEM education through its undergraduate Meyerhoff Scholars Program, graduate AGEP-PROMISE Program, and faculty ADVANCE Program, is not immune to the obstacles associated with diversifying the professoriate. This paper highlights UMBC's recognition of its successes, its

$14^{\text {th }}$ LACCEI International Multi-Conference for Engineering, Education, and Technology: "Engineering Innovations for Global Sustainability”, 20-22 July 2016, San José, Costa Rica. 
acknowledgement of areas for improvement, and its implementation of transformative actions through "Invitation to Engage," a heightened collaboration between the Provost Office and Graduate School that brings together the faculty, postdoctoral, and graduate communities to collectively address issues related to STEM pathway diversity. Through this renewed partnership UMBC intends to 1) (re)educate and empower our current faculty to take tangible actions to diversify the faculty body and 2) prepare our scholars from URM groups for positions in the STEM professoriate. The sections that follow provide background on UMBC, its faculty, postdoctoral, and graduate student bodies, information about successes from the PROMISE-AGEP, ADVANCE, and Faculty Diversity programs, including an identification of areas for improvement, and a discussion of "Invitation to Engage," our new collective framework for diversifying our faculty and the STEM professoriate writ large. It is our hope that UMBC's transparent discussion about this pressing issue, along with a presentations our revised approaches, will encourage other institutions to examine their current practices, and serve as an adaptable model to enact change. Through this paper we issue an open invitation for others to critically engage in these conversations and to take impactful and novel actions to repair the pathway to the STEM professoriate in order to meet the challenges around global sustainability in the $21^{\text {st }}$ century.

\section{THE UNIVERSITY OF MARYLAND, BALTIMORE COUNTY}

\section{A. The University of Maryland, Baltimore County}

$\mathrm{UMBC}$ is a mid-size public research university located in Baltimore, Maryland on the East Coast of the United States. A relatively young institution, celebrating its 50th anniversary in 2016, UMBC is proud of its long-standing history of inclusive excellence. Indeed, university president, Dr. Freeman A. Hrabowski III, an African American mathematician and international leader in STEM education, often refers to UMBC as an $H D I$-a historically diverse institution because the campus was racially integrated upon opening in 1966. UMBC has received numerous U.S. national accolades, including being named for six consecutive years (2009-2014) as the \#1 Up and Coming University (U.S. News \& World Report, 2014), as being among the top 35 most diverse national universities (U.S. News \& World Report, 2015), being \#4 in the "Most Innovative Schools" category (U.S. News \& World Report 2015), and being \#6 in undergraduate teaching, ahead of Yale Duke and Stanford (U.S. News \& World Report 2015).

B. Undergraduate, Graduate, Postdoctoral, and Tenured/Tenure Track Faculty Bodies

Although a predominately white institution (PWI), UMBC's undergraduate student body of 13,839 students is extremely diverse, consisting of 17\% African American, 6\% Hispanic/Latino, and 45\% women. This level of diversity is consistent among high number of African American, Hispanic/Latino and women undergraduate students who receive STEM bachelor's degrees. The diversity of undergraduate STEM bachelor's degrees is the result of the highly successful Meyerhoff Scholars program, founded in 1988 by President Hrabowski, the McNair Scholars program, and the Center for Women in Technology (CWIT) programs. Indeed, UMBC is poised to become the leading nonHistorically Black College or University (HBCU) producer of African American Bachelors in STEM who go on to get a STEM Ph.Ds.

This same level of diversity however is not reflected in UMBC's graduate, postdoctoral, or faculty bodies, with the disparities most pronounced in the STEM disciplines. Of UMBC's 2,596 graduate students, 12\% are African American, $4 \%$ are Hispanic, $48 \%$ are women, and $9 \%$ are URM women. Within the STEM disciplines, however, these percentages decrease to $11 \%$ African American, 3\% Hispanic/Latino, 35\%, and 5\% URM women. Regarding UMBC's 46 postdoctoral fellows, 42 of which are STEM Postdoctoral fellows, 10\% are African American, 0\% Hispanic Latino, 55\% are women, and $7 \%$ are URM women. Finally, of UMBC's 423 overall T/TT faculty body, 7\% are African Americans, 5\% are Hispanic/Latinos, $42 \%$ are women, and $6 \%$ are URM women. While the percentage of URM faculty at UMBC is above the national average, these percentages decrease within STEM to 3\% African American, 4\% Hispanic/Latino, 25\% women, and less than 1\% URM women. Comparatively, this data succinctly illustrates the narrowing of the STEM pathway from undergraduate to the professoriate for URMs, especially URM women. Although UMBC celebrates the diversity of its undergraduate student body, it recognizes the incongruence between these numbers and the diversity of its STEM URM graduate students, postdoctoral fellows, and faculty. Cognizant of this disparity of diversity, since the early 2000s UMBC has implemented numerous programmatic initiatives to recruit, retain, and advance underrepresented groups in its STEM graduate, postdoctoral, and faculty bodies. The subsequent section of this paper details three such interventions, PROMISE: Maryland's AGEP program in the Graduate School, and the ADVANCE program and Faculty Diversity Initiatives in the Office of the Provost.

\section{PROMISE: MARYLAND'S AGEP}

In 2001, UMBC collaborated with two other universities within the University System of Maryland, the University of Maryland College Park (UMCP) and the University of Maryland Baltimore (UMB), to develop a proposal for the National Science Foundation's Alliances for Graduate Education and the Professoriate (AGEP) program. The plan was to serve underrepresented graduate students in STEM fields from the three public research universities in Maryland. The program was funded in late 2002, and programming began in 2003. The initial award of $\$ 3.1$ million led to the development of diverse STEM graduate recruitment initiatives

$14^{\text {th }}$ LACCEI International Multi-Conference for Engineering, Education, and Technology: "Engineering Innovations for Global Sustainability”, 20-22 July 2016, San José, Costa Rica. 
for the Maryland's AGEP, now called PROMISE. The recruitment extended to schools and diversity programs throughout the U.S., including a special initiative and an MOU with the Ana G. Mendez University System (AGMUS) in Puerto Rico, in collaboration with Universidad Metropolitana (UMET) in San Juan, P.R. Recruitment efforts included weekend visitation programs, campus tours, and graduate school application information sessions. In addition to recruitment efforts, the PROMISE program developed a series of retention initiatives aimed toward providing professional development for diverse graduate students. These included large-scale, multi-campus programs such as the Summer Success Institute (SSI), the Dissertation House, and PROF-it: Professors-in-Training, and individual campus-based seminars and workshops on topics such as public speaking, and preparing for leadership.

There were increases in underrepresented graduate school enrollments and degree during these years for the PROMISE program. The total number of underrepresented STEM graduate student (MS \& Ph.D.) enrollees for the alliance of three institutions for Fall 2005 was 513. Data from the lead institution, UMBC, show that Ph.D. STEM enrollment increased from 54 at the start of the initial AGEP funding in 2002 to 75 in Fall 2005. In addition, UMBC's M.S. STEM enrollment increased from 48 in 2002 to 87 in 2005. During this time, surveys provided to students who participated in the PROMISE AGEP revealed three critical outcomes for student success:

1. Social networking, in-person and online, is critical. The ability to identify, connect, and cultivate social outlets outside academic departments, with fellow students who were also underrepresented, was an essential aspect of the program's success. Students are able to identify and build relationships with members of their campus community; a presence that they were unaware of prior to the program's inception. A very significant aspect of their social networking was the ability of the program to provide students with easy opportunities to foster relationships among graduate students across the campus boundaries. This realization of critical mass helped to reduce students' feelings of isolation. Further, the PROMISE program provided opportunities for students to share experiences and perceptions about issues that they thought were unique to their own personal experiences. The results of the sharing (via institutionalized mechanisms that facilitated the connections) revealed that the feelings of isolation were quite common among the larger underrepresented student population, both within and outside of STEM

disciplines. This shared experience, even when the experience might have been negative, provided students with the ability to bond and feel connected to a larger community.

2. Professional Development Seminars impact students' immediate and long-term behaviors. The PROMISE AGEP provided students with a varied assortment of educational, social, financial and emotional events and seminars that supplied students with numerous prospects to cultivate a variety of personal and professional skills. Students were invested in these seminars and events since they become active participants in the selection process. They report extensive support from PROMISE staff and respect for their opinions as evidenced by diligence to meet their needs with competent professional lectures and facilitators. Students found encouragement from networking experiences that resulted from events provided by PROMISE that were beyond the multi-campus setting, such as the ability to attend external, national conferences, e.g., the Southern Regional Education Board's (SREB) Compact for Faculty Diversity/Institute for Teaching and Mentoring.

3. Engaging in peer mentoring at an early stage in the student's academic career provides the student with the opportunity to cultivate their skill set for later academic obligations. The PROMISE AGEP established teams of advanced graduate students who served as official Peer Mentors within the various universities. The Peer Mentors identified themselves as role models in relationship to their fellow underrepresented graduate school classmates. This responsibility was viewed as a positive motivator toward the Peer Mentors' goals in graduate school, and assisted in their own degree completion and transitions to careers.

In 2008, UMBC received $\$ 1.5$ million in NSF funds to continue PROMISE: Maryland's AGEP with UMCP and $\mathrm{UMB}$, with the plan to increase the focus on retention and transition to the professoriate. This phase revealed that institutional commitment to a diversity initiative was critical to its success. Several programs that were created and implemented by PROMISE were institutionalized by the alliance university campuses and co-sponsored with academic departments (e.g., Success Seminars, dissertation completion activities). The PROMISE AGEP and UMBC's successful NSF ADVANCE program developed some collaborations and sharing of best practices, and many female STEM faculty are mentors and advisors for PROMISE students. Several of our women STEM faculty now have tenure and best practices from both PROMISE and ADVANCE have been used to hire new underrepresented U.S. citizen STEM faculty. In September 2010, the Dean of the Graduate School at the University of Maryland College Park convened a meeting with the Deans of all of the institutions in the University System of Maryland. Agenda items at that meeting included discussion of the CGS report, "A Path Forward," recruitment and retention of graduate students, and sharing resources. Discussions included developing a stronger network to share resources for graduate student professional development and providing teaching opportunities that could lead to cultivating professors for the University System of Maryland.

Data demonstrate that the PROMISE alliance has experienced success with recruitment, retention, and

$14^{\text {th }}$ LACCEI International Multi-Conference for Engineering, Education, and Technology: "Engineering Innovations for Global Sustainability", 20-22 July 2016, San José, Costa Rica. 
graduation of underrepresented STEM students. Examining phases, prior to the receipt of the first award and implementation of the PROMISE AGEP activities (2000-01 to 2002-03), the three universities in the current PROMISE alliance produced 81 underrepresented Ph.D.'s in STEM. During the first few years of the PROMISE program, 2003-04 to 2005-06, there were 96 underrepresented Ph.D. degrees awarded in STEM fields for the three campuses. The 2006-07 to 2008-09 years produced 127 underrepresented STEM Ph.D.'s. from the three campuses. This success led to the plan to expand the PROMISE AGEP to the other campuses within the University System of Maryland, include postdoctoral fellows, and develop additional partnerships with universities to expand future faculty training [4], [5], [6], and [7].

Additional funding from the National Science Foundation to expand the alliance to more public universities in Maryland came in the form of a pilot program in 2011 (PROMISE Pathways, \$150,000), and a full collaborative "AGEP-T" program in 2013 (PROMISE AGEP: Maryland Transformation, \$1.7 million). The PROMISE AGEP-T program now includes a postdoctoral program, stronger collaborations with the ADVANCE program, a Graduate Deans Council and a STEM Deans Council that focus on building faculty advocates and structures for transitioning students to faculty careers. PROMISE alumni have been in postdoctoral and faculty positions at institutions that include, but are not limited to, the NIH, MIT, the University of Maryland Eastern Shore, Clemson University, University of Pennsylvania, North Carolina State University, U.S. Naval Academy, Westpoint, Norfolk State University, University of Mississippi, UCLA, the University of Puerto Rico Mayaguez, University of Puerto Rico Rio Piedras.

The institutional commitment to diversity also includes programming from the National Institutes of Health's Meyerhoff Graduate Fellows Program, primarily focusing on biomedical sciences, including biomedically-motivated research areas of engineering. The Meyerhoff Graduate Fellows program has had more than $70 \mathrm{PhD}$ STEM alumni since 1996. Between 2003 and 2015, many of the Meyerhoff Graduate Fellows from UMBC also participate in PROMISE. UMBC's campus-wide commitment to diversity efforts facilitates collaborative opportunities between the programs to develop underrepresented STEM PhDs and prepare them for the professoriate. Programs such as PROMISE and the Meyerhoff Graduate Fellows program, which work to recruit, retain, and train students at the graduate level, demonstrate the diversifying the STEM professoriate can start with developing future STEM faculty at the student level.

\section{UMBC-ADVANCE AND FACULTY DIVERSITY INITATIVES}

A. $U M B C-A D V A N C E$

In 2003 UMBC received a 3.2 million dollar NSF ADVANCE Institutional Transformation (IT) grant to recruit, retain, and advance, women and URMs into its STEM T/TT faculty. At the grant's inception women comprised only $18 \%$ of its STEM faculty, with some STEM department having no women at all. Given the paucity of STEM women T/TT faculty, the grant had the ambitious task of creating a culture at UMBC that supports and promotes women STEM faculty throughout all stages of their career. To do so, UMBCADVANCE developed and implemented a series of highimpact initiatives, policies, and interventions aimed at transforming the institution.

To foster recruitment, UMBC-ADVANCE devised a comprehensive Family Support Plan that allows all faculty to reduce or otherwise modify workload, especially teaching duties, to maintain work/life balance while tending to a variety of family needs. This policy also includes a one-year tenure clock extension for pre-tenure faculty. This intervention has been highly successful with women who utilized the plan having a high rate of tenure. The plan proved so beneficial that in 2013 it was institutionalized for all thirteen institutions in the University of Maryland System. STEM departments developed Departmental Diversity Hiring Plans, in which they created a written plan detailing how they would recruit a diverse and inclusive pool of candidates for faculty searches, which has also resulted in more women candidates and ultimately women T/TT hires. The practice of women candidates for STEM faculty positions meeting with representatives from the Women and Science and Engineering (WISE) faculty group during interviews was also cited by new hires as a positive experience that informed their decision to accept position offers.

To retain women STEM faculty, UMBC-ADVANCE launched the Eminent Scholar Mentoring Program, as a means to disrupt the gendered and racial structural barriers that often preclude women's access to the critical mentoring and research networks, which serve as conduits of information and often provide access to national and international visibility in their research fields, two items directly linked to successful career advancement. This program facilitates a 2-year formal mentoring relationship between new UMBC female faculty member and a prominent researcher in their field. Mentors have provided mentees with advice on grant writing, networking opportunities at conferences, research collaborations, opportunities to present research, nominations for research awards, and counsel on mentoring students, career-life balance tips, and letters of support for tenure. Also, related to retention, the WISE faculty group began hosting a Faculty Sponsorship Committee every summer that provides women faculty with informal mentoring and feedback on their dossier materials for third-year contract, tenure, and promotion review. The UMBC-ADVANCE program also required STEM departments to clarify, write down, and disseminate policies related to tenure and promotion. UMBC-ADVANCE also began hosting semesterly Faculty ADVANCEment Workshops that share information needed to move successfully through the ranks of academia. Workshop topics include the Tenure and Promotion Process, Research

$14^{\text {th }}$ LACCEI International Multi-Conference for Engineering, Education, and Technology: "Engineering Innovations for Global Sustainability", 20-22 July 2016, San José, Costa Rica. 
Development, Maximizing the Potential of Mentoring Relationships, Curating Your Digital Identity, and Roads to Leadership: Exploring Your Options with Intention.

Finally, to encourage women's advancement into leadership positions, UMBC-ADVANCE devised the ADVANCE Leadership Cohort Program, which uses a cohort model and focuses on intentional career advancement. Now in its 4th cohort, each group has focused on such areas as administrative leadership, leadership styles, departmental leadership, leadership in scientific research centers, the gendered dimensions of leadership, and career/life balance. This program has been highly effective with cohort members now in such positions at UMBC and other institutions as Dean of the College of Engineering and Information Technology, Associate Dean of the College of Engineering and Information Technology, Dean of the Graduate School, Vice Provost for Faculty Affairs, Director of the Center for Women in Technology, Director of the Center for Space, Science and Technology.

It was evident at the conclusion of NSF-funding that these policies and programmatic interventions had a transformative impact on the climate and culture in UMBC's STEM disciplines. During the grant, there was a $56 \%$ increase in the number T/TT women STEM faculty (2003 N=30; 2008 $\mathrm{N}=47$ ), with every STEM department now having at least two women STEM faculty members, and women faculty were $25 \%$ of STEM faculty. UMBC was clearly moving toward critical mass; however, the overwhelming majority of these $\mathrm{T} / \mathrm{TT}$ women in STEM were White or Asian. At the conclusion of the grant, $2 \%$ of women STEM faculty were from URM groups.

\section{B. Faculty Diversity Initiatives}

In 2011, UMBC institutionalized the ADVANCE program and simultaneously launched the Faculty Diversity Initiative in the Office of the Provost with the intent of adapting and extending the promising practices learned from ADVANCE to increase the number of T/TT URM faculty across the entire campus. That spring the Executive Committee on the Recruitment, Retention, and Advancement of Underrepresented Minority Faculty (URM Executive Committee), comprised of tenured URM faculty, was convened as a parallel committee to the ADVANCE Executive Committee, to guide the development and implementation of initiatives to address issues and concerns specifically associated with the hiring, retention, and advancement of URM faculty at UMBC. In the area of recruitment, UMBC began tracking the diversity of its interview pools, and after purchasing Interfolio, an online faculty search software, in 2013, UMBC began tracking the gender, race, ethnic, ability, and veteran diversity of its initial applicant pools, long lists, and short lists, in addition to oncampus interviews. Also, working with the Office of the Provost, the Dean of each college implemented Implicit Bias Training for all Search Committees. The Executive Committee created a Postdoctoral Fellowship for Faculty Diversity, a twoyear program to support promising recent Ph.D. recipients committed to diversity in the academy with the goal of preparing them for possible tenure-track appointments at UMBC. Of the eight fellows who have participated in the program thus far, however, only one fellow was from a STEM discipline, and only one fellow has been converted to a T/TT faculty position at UMBC. The Dean of the College of Natural and Mathematical Sciences is currently developing a preprofessoriate fellowship better tailored to the STEM disciplines. In addition to these programs, UMBC's Faculty Diversity Initiative engaged in a robust outreach campaign by developing a Faculty Diversity Brochure and companion Faculty Diversity website. Along with this visibility campaign, UMBC also sends a delegation of faculty every year to recruit for UMBC's faculty openings at the Southern Regional Education Board conference, the largest gathering of minority students in the country.

As part of its retention efforts, this committee oversaw the institutionalization of the Eminent Scholar Mentoring program to all new URM faculty, and eventually all new UMBC faculty in 2013. Outside of the Executive Committee, the Office of the Provost provides funding for such community based faculty groups as the Black Faculty Committee, the Latino/Hispanic Faculty Association, the LGBT Faculty/Staff Association, the WISE Faculty Group, and the Women's Faculty Network. The faculty groups routinely meet with candidates for faculty positions and provide a community of support for faculty on campus.

\section{TAKING STOCK: LOOKING BACK AND MOVING FORWARD}

Notwithstanding these initiatives, UMBC remains unsatisfied with the number of URM faculty, particularly in STEM, where gains have been minimal. UMBC also recognizes that in addition to recruitment, more emphasis must be placed on initiatives related retention and advancement. While the PROMISE program has had relatively greater success with supporting URM graduate students and postdocs, if we are to provide the robust exchange of diverse perspectives and ideas, innovative and collaborative research opportunities, and the role models and mentors necessary to produce the cutting edge research to address problems related to global sustainability, and to prepare the next generation of STEM researchers to do the same, we must do more to recruit, retain, and advance URM faculty at UMBC. In 2016, UMBC celebrates its 50th anniversary; however, as we look back, we take stock of our accomplishments, recognize our shortcomings, and look forward with a renewed commitment to engage with one another to transform the diversity of our faculty body.

\section{INVITATION TO (RE) ENGAGE: TOWARD NEW COLLABORATIVE EFFORTS}

$14^{\text {th }}$ LACCEI International Multi-Conference for Engineering, Education, and Technology: "Engineering Innovations for Global Sustainability", 20-22 July 2016, San José, Costa Rica. 
UMBC's PROMISE, ADVANCE and Faculty Diversity Initiatives, after reviewing programmatic strengths and weaknesses, are redesigning our approaches to broadening participation through new interventions that (re)educate and empower our current faculty to take tangible actions to diversify the professoriate and better prepare our URM graduate students and postdoctoral fellows for faculty positions in STEM. In order to achieve these goals, all stakeholders must engage with one another and we must break down barriers among faculty, postdoctoral fellows, and graduate students. Additionally, we must alleviate institutional divisions between the diversity efforts happening in the Provost Office and the Graduate School.

To foster collaboration between the Provost Office and Graduate School diversity initiatives, in 2015, the Director of PROMISE was added to the URM Executive Committee, which guides faculty diversity initiatives within the Provost Office. Moreover, the Director of PROMISE and the Coordinator for Faculty Diversity Initiatives and the ADVANCE Program began regularly meeting outside of the URM Committee to provide programmatic feedback, support, and identify areas of collaboration. These conversations have resulted in the joint-initiative "Invitation to Engage," which seeks to deliberately foster community across the faculty, graduate, and postdoctoral bodies. We believe that a renewed attention on engagement is the key to diversifying the STEM pathway at UMBC. Working together, under the framework of intentional engagement, UMBC Faculty Diversity Initiatives is establishing four new initiatives 1) UMBC-STRIDE, 2) Faculty Field Networking, 3) Emerging Scholars, and 4) the University System of Maryland PROMISE AGEP Research Symposium and Professional Development Conference.

In an expansion of the implicit bias search committee training, the deans currently lead that, ADVANCE and Faculty Diversity Initiatives formed UMBC-STRIDE, based on the model developed at the University of Michigan. The UMBC-STRIDE team is comprised of highly respected faculty fellows from each college that provide advice and counsel to departments and faculty search committee members on the best practices for recruiting well-qualified and diverse candidates for faculty positions. The STRIDE Committee provides guidance on the retention and advancement of candidates offered and hired for positions at UMBC. The UMBC-STRIDE Committee also leads annual college-based workshops on implicit bias for faculty and administrators. We believe that this peer-to-peer faculty-led training model will serve a more engaging tool for raising awareness about implicit bias and devising real strategies to overcome its effects on the faculty search process.

In addition to UMBC-STRIDE, UMBC's Faculty Diversity Initiatives is committed to helping departments shift to more active models of recruiting and network building. $\mathrm{UMBC}$ recognizes that placing an advertisement and passively collecting applications is an outdated model for assembling a diverse candidate pool. In order to publicize faculty openings and reach the largest audience, search committees are encouraged to engage in network building by using social media, maximizing attendance at conference venues, and leveraging colleagues to identify and attract prospective candidates. Moreover, UMBC recognizes that connections between departments and prospective applicants need to begin at an earlier stage. Indeed, before a department has a faculty opening, they should already have a robust network of scholars, who they have continuously cultivated a relationship with, to engage with about opportunities. To build this network, there is now an explicit expectation that faculty members engage in Faculty Field Networking when they attend targeted disciplinary conferences and minority-targeted STEM conferences by routinely taking and sharing information related to UMBC's faculty openings and commitment to the value of diversity. Examples of minority targeted conferences include the Latin American and Caribbean Consortium of Engineering Institutions Conference, the Society for the Advancement of Chicanos and Native Americans in Sciences Conference, Annual Biomedical Research Conference for Minority Students, the Annual Ford Foundation meeting, the Grace Hopper Celebration of Women in Computing Institute, and the Institute of Electrical and Electronic Engineers meeting. In this new model, all UMBC faculty have a shared responsibility for identifying future colleagues. To enable departments to establish relationships and networks with up-and-coming STEM scholars early on, in 2016 UMBC piloted the Emerging Scholars Program/Get to Know UMBC Program. This pilot initiative provides departments, centers, and programs with funding to host advanced graduate students and junior faculty from underrepresented communities identified through faculty field networking on campus for a two-day immersion experience. The Emerging Scholars Program seeks to (a) elevate the visibility of UMBC within networks of graduate students and junior faculty working with underrepresented communities; (b) increase the number of job applicants from underrepresented communities; (c) strengthen information sharing and candidate identification strategies for future recruitment of underrepresented faculty; and (d) enhance the exposure of UMBC students to a pedagogically and demographically diverse faculty.

Finally, in Spring 2016, PROMISE is hosting the University System of Maryland PROMISE AGEP Research Symposium and Professional Development Conference. This conference replaces the former PROMISE Research Symposium, and adds a professional development component that will prepare graduate students and postdoctoral fellows for STEM faculty positions. This conference seeks to provide a venue that will allow students to present their work at any stage, receive feedback in preparation for presenting at larger venues, and provide training that will prepare participants for faculty careers. In the spirit of engagement, the research symposium includes a roundtable session intended to

$14^{\text {th }}$ LACCEI International Multi-Conference for Engineering, Education, and Technology: "Engineering Innovations for Global Sustainability”, 20-22 July 2016, San José, Costa Rica. 
demystify the faculty search process. This special session includes invited UMBC faculty mentors, with experience serving on search committees, who will share insiderinformation with graduate and postdoctoral attendees. We believe this special session will be mutually beneficial in providing graduate students and postdoctoral fellows with critical information about the search process while providing UMBC Faculty with the opportunity to participate in faculty field networking to develop their scholar networks for future openings.

\section{OPEN INVITATION TO ENGAGE}

The lack of underrepresented groups in the STEM professoriate is longstanding and pervasive. While there is greater awareness and around gendered and ethno-racial disparities in STEM, and meaningful attempts to address this problem, there has been little progress in augmenting the numbers. Given persistent lack of diversity in the STEM professoriate, it is time for critical self-examination within institutions of higher education to identify what more can be done. In short, we need to radically (re)engineer our approaches to faculty diversity to ensure that we are capable of producing the innovative research and solutions to ensure a globally sustainable planet. Unless we are able to appreciate and harness the perspectives, experiences, and talents of individuals and groups, we will surely fail at this mission and the mission of our collective institutions.

Conversations around diversity in the STEM pathway to professoriate are often difficult begin and difficult to partake in, but necessary if we are to truly enact change. For those change agents who are already working on these issues, we need to do more to invite new voices to engage in these difficult dialogues and support and encourage their participation in meaningful interventions to transcend boundaries. An invitation to engage is easy to extend and can be done anywhere, within a meeting, department, university, conference, or even over coffee. UMBC's work to diversity the STEM professoriate is far from over, but we hope that our candid discussion about our struggles recruiting, retaining, and advancing a diverse and excellent STEM faculty and our innovative solutions will inspire other universities to do the same. We end this paper with an open invitation for our readers to engage our new approaches to faculty diversity and to develop and share their own.

\section{ACKNOWLEDGMENTS}

The authors acknowledge supportive actions and connection to initiatives from the following programs of the National Science Foundation: The Broadening Participation in Engineering Program, PROMISE AGEP: Maryland Transformation (PROMISE: Maryland's Alliance for Graduate Education and the Professoriate - AGEP-T), The Louis Stokes Alliance for Minority Participation Bridge to the
Doctorate Program (LSAMP-BD), and ADVANCE: Increasing the Participation and Advancement of Women in Academic Science and Engineering Careers. The following units and departments at UMBC also receive acknowledgment: Dr. Philip Rous, Provost and Senior Vice Provost for Academic Affairs, Dr. Patrice McDermott, Vice Provost for Faculty Affairs, Dr. Janet Rutledge, Dean of the Graduate School and Vice Provost for Graduate Education; the Executive Committee on the Recruitment, Retention, and Advancement of Underrepresented Minority Faculty, the ADVANCE Executive Committee, and the UMBC-STRIDE Committee.

\section{REFERENCES}

[1] Yoder, B.L., (2014). "Engineering by the numbers." American Society for Engineering Education, https://www.asee.org/papers-andpublications/publications/14_11-47.pdf.

[2] Yoder, B.L., (2014)."Engineering by the numbers." American Society for Engineering Education, https://www.asee.org/papers-andpublications/publications/14_11-47.pdf.

[3] U.S. Census Bureau: State and County QuickFacts. Data derived from Population Estimates, American Community Survey, Census of Population and Housing, State and County Housing Unit Estimates, County Business Patterns, Nonemployer Statistics, Economic Census, Survey of Business Owners, Building Permits. (2014). http://quickfacts.census.gov/qfd/states/00000.html.

[4] Tull, R. G., \& Carter-Veale, W. (2014, May). Structured Interventions for Underrepresented Students and Faculty Members in STEM. In D. E. Chubin \& A. L. DePass. (Eds.). Understanding interventions that broaden participation in research careers: Intervening to Critical Mass (vol. V, pp. 29-32). Summary of conference presentation at the 2012 Understanding Interventions that Broaden the Participation in Research Careers conference, Baltimore, MD.

[5] Tull, R. G., Rutledge, J.C., Warnick, J. W., \& Carter, F. D. (2012). PROMISE: Maryland's Alliance for Graduate Education and the Professoriate Enhances Recruitment and Retention of Underrepresented Minority Graduate Students. Academic Medicine, 87(11), p. 1562-1569.

[6] Ponjuan, L., Gasman, M., Hirshman, E., \& Esters, L. L. (2011). "A New Hope: Recruiting and Retaining the Next Generation of Faculty of Color", Association of Public and Land-Grant Universities Issue Brief - Council on Access, Diversity and Excellence (https://www.aplu.org/netcommunity/)

[7] Rutledge, J.C., Carter-Veale, W.Y. \& Tull, R. G. (2011). Successful PhD Pathways to Advanced STEM Careers for Black Women in Beyond Stock Stories and Folktales: African Americans' Paths to STEM Fields, Vol. 11., H. T. Frierson and W. F. Tate, Eds. United Kingdom: Emerald Group Publishing Ltd.

$14^{\text {th }}$ LACCEI International Multi-Conference for Engineering, Education, and Technology: "Engineering Innovations for Global Sustainability", 20-22 July 2016, San José, Costa Rica. 